\title{
A Tobacco S-like RNase Inhibits Hyphal Elongation of Plant Pathogens
}

\author{
Karine Hugot, Michel Ponchet, Antoine Marais, Pierre Ricci, and Eric Galiana \\ INRA, UIPMSV, Villa Thuret, BP 2078, F-06606, Antibes cedex, France \\ Submitted 4 October 2001. Accepted 26 November 2001.
}

\begin{abstract}
Ribonuclease (RNase) NE gene expression is induced in tobacco leaves in response to Phytophthora parasitica. Using antibodies directed against $\mathrm{RNase} N E$, we demonstrate that RNase NE is extracellular at the early steps of the interaction, while the fungal tip growth is initiated in the apoplastic compartment. After production in Pichia pastoris and biochemical purification, we show that the S-like RNase NE inhibits hyphal growth from $P$. parasitica zoospores and from Fusarium oxysporum conidia in vitro. Conversion into an enzymatically inactive form after mutagenesis of the active site-histidine 97 residue to phenylalanine leads to the suppression of this activity, suggesting that RNase NE inhibits the elongation of germ tubes by degradation of microbial RNAs. Exogenous application of RNase NE in the extracellular space of leaves inhibits the development of $P$. parasitica. Based on its induction by inoculation, its localization, and its activity against two plant pathogens, we propose that RNase NE participates in tobacco defense mechanisms by a direct action on hyphal development in the extracellular space. The RNase activity-dependent antimicrobial activity of the S-like RNase NE shares similarities with the only other biological activity demonstrated for plant RNases, the inhibition of elongation of pollen tubes by the S-RNase in gametophytic self-incompatibility, suggesting a functional link between self and nonself interactions in plants.
\end{abstract}

Ribonucleases (RNases) are ubiquitous components of living cells, and it is now known that they are involved in functions other than the turnover of cellular RNAs. In plants, the only clearly established, specialized function of RNases is associated with gametophytic self-incompatibility (Dodds et al. 1996a; Kao et al. 1996). Indeed, the expression of the S-RNase gene in the pistil of self-incompatible flowers is required for rejection of the pollen bearing the same S-allele (Lee et al. 1994; McClure et al. 1989; Murfett et al. 1994). The discovery of the S-RNases led to the identification of a large number of related plant RNases in self-compatible species, called S-like RNases, indicating that this enzyme family could have a more fundamental role in RNA decay in plants. The family of S- and S-like RNases is a subset of the family of enzymes typified by the fungal RNase T2. This family is the most widespread RNase family, with representatives in viruses, bacteria, fungi, amoebas, and animal species (Irie et al. 1997). S- and S-like RNases from plants show five highly conserved regions named from C1 to C5 (Green et al. 1994). Two of these regions, C2 and $\mathrm{C} 3$, are found throughout the T2 family and contain two of the three active site histidine residues that are required for the

Corresponding author: Eric Galiana; E-mail: galiana@antibes.inra.fr catalytic activity of RNase Rh of Rhizopus niveus (Oghi et al. 1992). Expression of S-like RNase genes has been described during senescence in Arabidopsis thaliana and Lycospersicum esculentum (Lers et al. 1998; Taylor et al. 1993), in response to phosphate limitation in A. thaliana, L. esculentum, and Nicotiana alata (Bariola et al. 1994; Dodds et al. 1996; Kôck et al. 1995), and during xylogenesis in Zinnia elegans (Ye and Droste 1996).

On the other hand, many observations based on enzymatic activity detection suggest the implication of RNases in defense mechanisms in plants. Schrauwen and Linskens (1972) have proposed that pistil ribonucleases may be involved in defense against pathogens. The nutrient-rich stigmatic and transmitting tissues of the pistil are particularly vulnerable to attack by fungal or bacterial pathogens. The high level of ribonuclease activity, along with other hydrolytic enzymes and pathogenesisrelated proteins identified in the pistil, may explain how pistils escape colonization by pathogens. Lusso and Kuc (1995) have reported the increase of ribonuclease activity after challenge inoculation with viral and fungal pathogens in tobacco plants previously induced for systemic acquired resistance (SAR) with tobacco mosaic virus. Moreover, wounding is known to induce rapid increases in RNase activities (Farkas 1982). More recently, mechanical wounding has been shown to rapidly induce two S-like RNase genes, Z RNase II from Z. elegans (Ye and Droste 1996) and LE RNase from tomato (Lers et al. 1998).

We have previously shown that a gene encoding an S-like extracellular ribonuclease, RNase NE, is expressed in tobacco leaves after inoculation with the oomycete Phytophthora parasitica (Galiana et al. 1997). We have proposed that extracellular RNases of plants could participate in defense mechanisms by direct action on the development of pathogens in the intercellular space. Based on its specific expression and its signal sequence for extracellular localization, RNase NE is a candidate for this role in tobacco.

Here, we describe the antimicrobial activity of purified RNase NE against two plant pathogens. We show that RNase $\mathrm{NE}$ inhibits the elongation of hyphal tubes in a concentrationand enzymatic activity-dependent manner. The data also suggest that the antimicrobial activity is mediated by intracellular degradation of fungal RNAs after translocation of the NE protein through Golgi structures.

\section{RESULTS}

Expression and purification of recombinant RNase NE.

The predicted amino acid sequence for RNase NE includes a putative $\mathrm{N}$-terminal secretion signal with a potential cleavage site after residue Ala27 and a mature RNase region of 204 amino acids with a calculated molecular mass of 22,391 Da 
(Dodds et al. 1996b). The NE sequence required for coding the mature secreted RNase NE (residue Ala28 to Phe231) was cloned in frame with the signal sequence of the $\alpha$-factor, which has been demonstrated to be very efficient in Pichia pastoris. After induction of NE gene expression, sodium dodecyl sulfate-polyacrylamide gel electrophoresis (SDS/PAGE) analysis and RNase activity staining gel assays revealed the accumulation of a protein with an apparent molecular mass of $22 \mathrm{kDa}$ (Fig. 1A). An RNase activity in the same molecular mass range was detected in the culture media of pPIC9-NE yeast transformants (Fig. 1B). In control experiments, yeast clones obtained after transformation with the shuttle vector pPIC9 did not secrete any protein with RNase activity in the presence of methanol. This confirmed that the recombinant NE protein exhibits a ribonuclease activity, as was expected from the cDNA and deduced amino acid sequence (Dodds et al. 1996b). RNase NE was further purified from culture filtrate by using a two-step, column chromatography strategy. Its purity and the efficiency of the purification $(20 \mathrm{mg} / \mathrm{l})$ were evaluated by high-performance liquid chromatography (HPLC) analysis (Fig. 1C). RNase $\mathrm{NE}$ had a specific activity of 1.5 units $\mathrm{min}^{-1} \mathrm{mg}^{-1}$ and an optimal $\mathrm{pH}$ range between 5 and 6 (data not shown).

\section{Extracellular localization of RNase NE.}

We have previously reported induction of the NE gene in tobacco leaves in response to $P$. parasitica inoculation (Galiana et al. 1997). Here, the study was expanded at the protein level. We have analyzed the accumulation of NE protein in Phytophthora-inoculated leaves by using antibodies directed against the purified recombinant NE protein. After SDS/PAGE on a $15 \%$ gel and Western blot analysis, a protein band with an apparent molecular mass of 22,000 Da was detected in crude extracts or in intercellular fluids of tobacco leaves. The
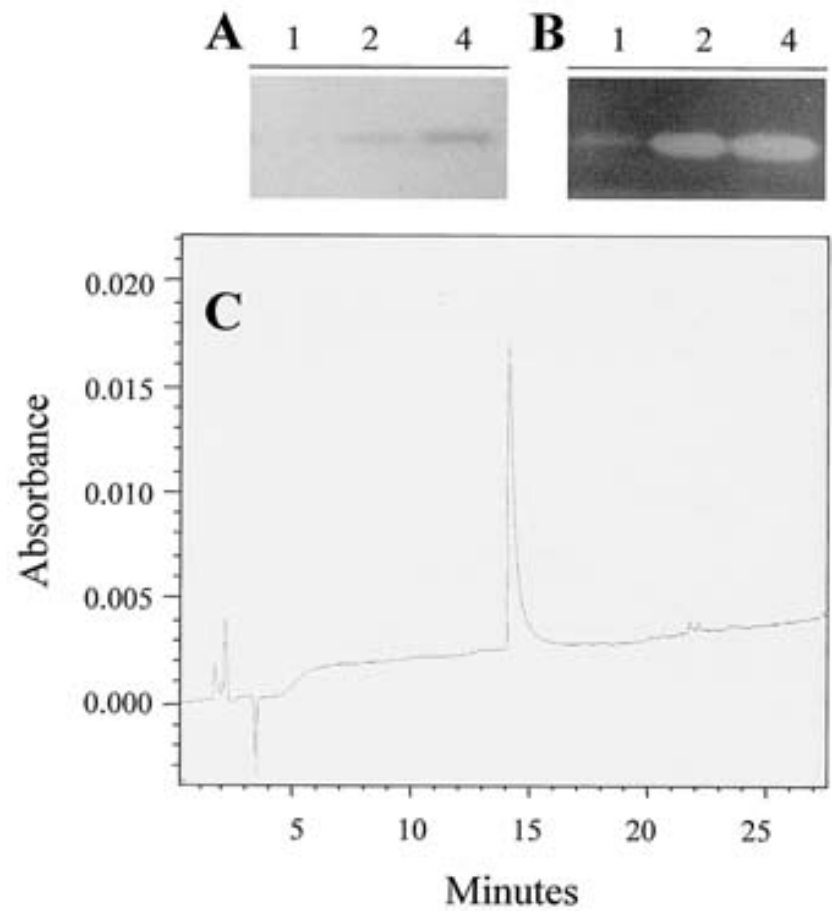

Fig. 1. Expression and purification of RNase NE from Pichia pastoris. Sodium dodecyl sulfate-polyacrylamide gel electrophoresis analysis of A, silver-stained proteins and $\mathbf{B}$, ribonuclease activity from culture filtrates of yeast clones and at different times (1,2, and 4 days) after methanol treatment. C, High-performance liquid chromatography (HPLC) analysis of purified NE protein. HPLC analysis detected only one peak, and the peak contained the ribonuclease activity. molecular mass of this single band is in the range predicted for the tobacco RNase NE from the cDNA sequence. RNase NE contains no potential N-glycosylation sites (Dodds et al. 1996b). This band was only detected when the NE gene was activated after Phytophthora inoculation (Galiana et al. 1997); it was not detected with preimmune serum (data not shown). Immunoblotting experiments showed that RNase NE was not detected in the very early hours after inoculation, but started to accumulate $8 \mathrm{~h}$ after inoculation, and was only detected in the intercellular fluid, while it was undetectable in intracellular fractions (Fig. 2A). The intracellular detection of malate dehydrogenase (Miller et al. 1998) was used as a control in these experiments (Fig. 2B). Thus, RNase NE is targeted to the extracellular space and accumulates into the leaf apoplasm precisely when the pathogen starts to initiate its development.

\section{In vitro antimicrobial effect of purified enzyme NE.}

A slide assay was used to determine the effects of the purified RNase NE recombinant protein on the in vitro growth of $P$. parasitica and Fusarium oxysporum. Protein was added to a suspension of zoospores or conidia just after their release from the mycelium. Microscopic observations and cell counting performed after $2 \mathrm{~h}$ indicated that the viability and the motility of the spores of both fungi were not affected in the presence of RNase NE, even at the highest tested concentration of $500 \mu \mathrm{g} / \mathrm{ml}$ (data not shown). On the other hand, observations performed after $24 \mathrm{~h}$ indicated that in the presence of RNase NE $(50 \mu \mathrm{g} / \mathrm{ml})$, hyphal elongation was significantly reduced by up to 60 and $90 \%$ for $P$. parasitica and F. oxysporum, respectively (Fig. 3). Under these conditions the kinetics of $P$. parasitica growth were monitored for $36 \mathrm{~h}$. Figure 4A shows that in the presence of RNase $\mathrm{NE}$, the average length of germ tubes remained almost unchanged from 12 to $36 \mathrm{~h}$, indicating that RNase NE strongly reduced, or even stopped, hyphal elongation. At time point $24 \mathrm{~h}$, we assessed the inhibitory effect of RNase NE at different concentrations ranging from $0.1 \mu \mathrm{g} / \mathrm{ml}$ to $250 \mu \mathrm{g} / \mathrm{ml}$. RNase NE inhibited $P$. parasitica growth in a concentration-dependent manner with a minimum inhibitory concentration of $0.5 \mu \mathrm{g} / \mathrm{ml}$, resulting in a reduction of hyphal growth to less than $20 \%$ of the control, and an IC50 value of $10 \mu \mathrm{g} / \mathrm{ml}$ (Fig. 4B).

\section{Influence of ribonuclease activity on the antihyphal elongation effect.}

To test the involvement of the enzymatic activity of RNase NE in its antimicrobial activity, we have produced in Pichia pastoris an NE protein that contains a mutation in its active site. Specific His residues are required for the catalytic function of the RNase $\mathrm{Rh}$ and $\mathrm{S}$-RNases and are conserved

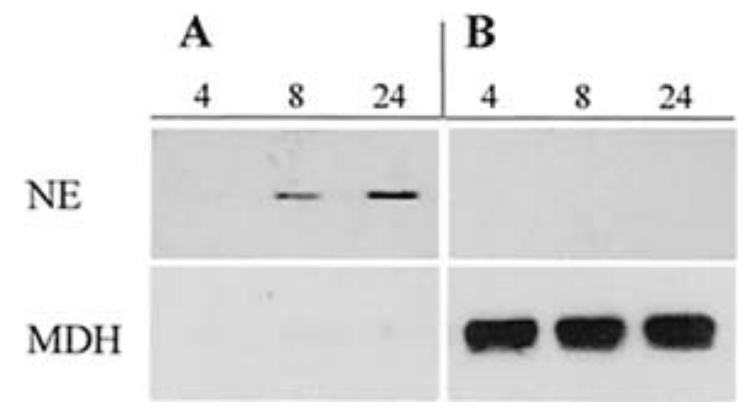

Fig. 2. Western blotting analysis of extracellular RNase NE from Phytophthora-inoculated leaves. A, Intercellular fluids and $\mathbf{B}$, intracellular fractions were prepared from the leaves of tobacco plants at different times $(4,8$, and $24 \mathrm{~h})$ after fungal inoculation. After sodium dodecyl sulfate-polyacrylamide gel electrophoresis and gel blotting, proteins $(5 \mu \mathrm{g})$ were incubated with rabbit antibodies against RNase NE or against the malate dehydrogenase (MDH). 
throughout the T2 family (Oghi et al. 1992). Therefore, we have mutated one of them, His 97 to Phe, by site-directed mutagenesis. As expected, Western blot analysis led to the detection of the NE and NE-H97F proteins, while RNase activity gel analysis showed enzymatic activity of only the wild-type RNase NE (Fig. 5A and B). Indeed, in the same experiment, the NE-H97F protein did not exhibit detectable RNase activity. Hyperchromicity could not be performed because of the very low level of RNase activity. The mutated protein was then tested for its effect on $P$. parasitica hyphae elongation and compared to that caused by RNase NE. Figure 5C shows how the loss of RNase activity leads to the restoration of the complete development of the oomycete. Indeed, at the different time points, the average length of germ tubes was similar to that measured without any RNase NE treatment as illustrated in Figure 4A. Thus the abolition of RNase activity suppresses the antimicrobial activity of RNase NE.

\section{Inhibitory effect of brefeldin A on RNase NE antimicrobial activity.}

The involvement of enzymatic activity in the RNase NE antimicrobial effect strongly suggests that this effect is mediated by the translocation of the NE protein into the pathogen cell where it degrades RNAs. To investigate whether RNase NE could be transported to the fungal Golgi structures, we tested the effect of brefeldin A on the antimicrobial activity of NE. In the presence of brefeldin A, the Golgi structure disassembles and gets redistributed into the endoplasmic reticulum (Chardin and McCormick 1999). We tested the effect of brefeldin A on P. parasitica growth and found that $4 \mu \mathrm{g}$ of brefeldin A per $\mathrm{ml}$ reduced hyphal elongation by $24 \%$ after $24 \mathrm{~h}$ (data not shown). When fungal cell cultures were treated with both brefeldin A (4 $\mu \mathrm{g} / \mathrm{ml})$ and RNase NE $(50 \mu \mathrm{g} / \mathrm{ml})$ the antimicrobial activity of NE protein $(50 \mu \mathrm{g} / \mathrm{ml})$ was reduced by $50 \%$ (Fig. 6A). Thus, despite its weak effect on in vitro growth, brefeldin A protected $P$. parasitica against RNase NE treatment. In dose-effect assays, the IC50 value was $50 \mu \mathrm{g} / \mathrm{ml}$ with brefeldin A (Fig. 6B) compared with $10 \mu \mathrm{g} / \mathrm{ml}$ without brefeldin A.

\section{Influence of RNAse NE on $\boldsymbol{P}$. parasitica growth into tobacco leaves.}

To test for a possible in vivo role for the RNase NE, we first developed experiments to estimate the amount of protein in Phytophthora-inoculated leaves. Twenty-four hours after leaf infection, intercellular fluids were prepared and subjected to SDS/PAGE on $15 \%$ gel and to an immunoblot analysis. As controls, we used different amounts of purified RNase NE, ranging from $10 \mathrm{ng}$ to $500 \mathrm{ng}$. Figure $7 \mathrm{~A}$ shows that the amount of protein in $10 \mu \mathrm{l}$ or $100 \mu \mathrm{l}$ of intercellular fluid could be estimated to be 10 to $20 \mathrm{ng}$ or 50 to $100 \mathrm{ng}$, respectively. Thus the RNase NE concentration in intercellular fluid from Phytophthora-inoculated leaves could be evaluated to 0.5 to 2 $\mu \mathrm{g}$ per $\mathrm{ml} 24 \mathrm{~h}$ after inoculation.

We then introduced the RNase NE in the leaf extracellular space and tested its effect on the growth of $P$. parasitica. To immediately increase the amount of RNase NE in the apoplasm, tobacco leaves were inoculated by infiltrating a zoospore suspension in the presence of RNase NE. When the concentrations of RNase NE ranged from 0.5 to $5 \mu \mathrm{g}$ per ml, no significant effect on disease symptom expression or on fungal growth were measured when compared with inoculation controls in the presence of RNase NE-H97F or bovine serum albumin (data not shown). When the concentration reached $50 \mu \mathrm{g}$ per $\mathrm{ml}$, the spread of the invaded surface 2 days after infection was limited to $1.4 \mathrm{~cm}^{2}$, leading to a $40 \%$ reduction in fungal growth compared with the inoculated zones in the presence of control proteins (Fig. 7B).

\section{DISCUSSION}

We show here that a tobacco extracellular RNase inhibits the elongation of germ tubes produced by the spores of two unrelated plant pathogens, $P$. parasitica and $F$. oxysporum. We demonstrate that the antimicrobial activity requires enzymatic activity of the RNase. In vivo experiments based on RNase NE treatment of $P$. parasitica-inoculated leaves confirmed the RNase NE-antimicrobial property. Many results have accumulated over the last years suggesting a function of RNases in plant defense mechanisms (Farkas 1982; Lers et al. 1998; Lusso and Kuc 1995; Schrauwen and Linskens 1972; Ye and Droste 1996). Based on our results, we propose such a role for RNase NE as a direct action against pathogens in the apoplastic compartment.

Many plant RNases have been localized outside the cell or within the vacuole, which is surprising for enzymes whose substrate is typically cytoplasmic. We have previously shown that an inoculation with $P$. parasitica induces a local expression of the NE gene in tobacco (Galiana et al. 1997). Here, we confirm this induction at the protein level and demonstrate that RNase NE is extracellular. After microbial penetration into the plant, a set of apoplastic antifungal molecules is one of the first barriers to pathogen attack. Antifungal activities have been demonstrated for small molecules, such as phytoalexins, or for proteins, such as some pathogenesis-related proteins (Niderman et al. 1995; Sela-Buurlage et al. 1993). The effective concentrations for RNase NE in vitro ( 1 to $50 \mu \mathrm{g} / \mathrm{ml})$ are in the same

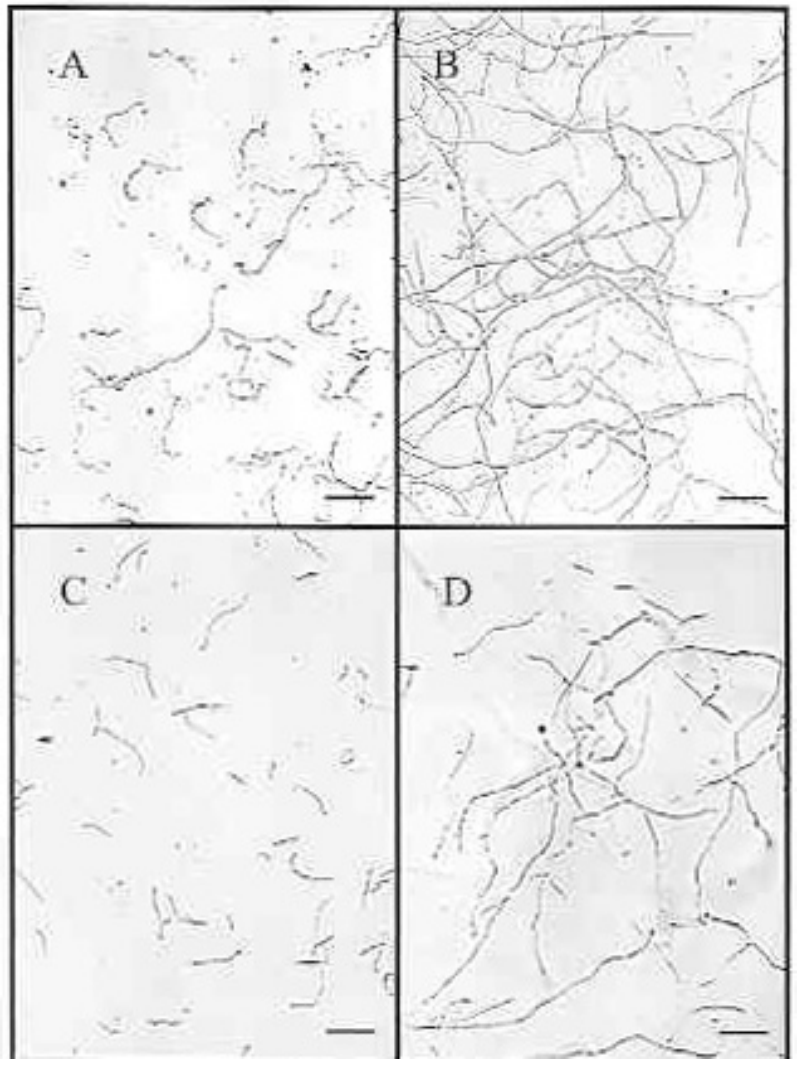

Fig. 3. Inhibition of elongation of fungal germ hyphae by purified RNase NE. Zoospores or conidia were incubated just after their release in 10 $\mathrm{mM}$ MES buffer with or without RNase NE $(50 \mu \mathrm{g} / \mathrm{ml})$ for $48 \mathrm{~h}$. A, The length of Phytophthora parasitica filaments was reduced by up to $50 \%$ in the presence of RNase NE, with a mean length of $220 \mu \mathrm{m} \pm 37$, while B, the mean length in control experiments was $650 \mu \mathrm{m} \pm 165$. For Fusarium oxysporum, $\mathbf{C}$, in the presence of $\mathrm{RNase} \mathrm{NE}$ the length of germ tubes was reduced by up to $90 \%$ with a mean length of $50 \mu \mathrm{m} \pm 20$ while in $\mathbf{D}$, control experiments the mean length was $500 \mu \mathrm{m} \pm 200$. Bar sizes $=$ $100 \mu \mathrm{m}$. 
range as other plant antifungal proteins identified so far, such as defensins (Terras et al. 1992). It is also consistent with concentrations of RNase NE $(0.5$ to $2 \mu \mathrm{g} / \mathrm{ml})$ in intercellular fluid from $P$. parasitica-inoculated leaves. When we delivered RNase NE into the apoplastic fluid of leaves, we also found that increasing the RNase NE concentration prevents the in planta growth of $P$. parasitica. However, in planta-effective concentrations were higher than in vitro-effective concentrations and than estimated concentrations in intercellular fluid of $P$. parasitica-inoculated leaves. Thus, the pathogen is less sensitive to the antimicrobial property of RNase NE when it colo-
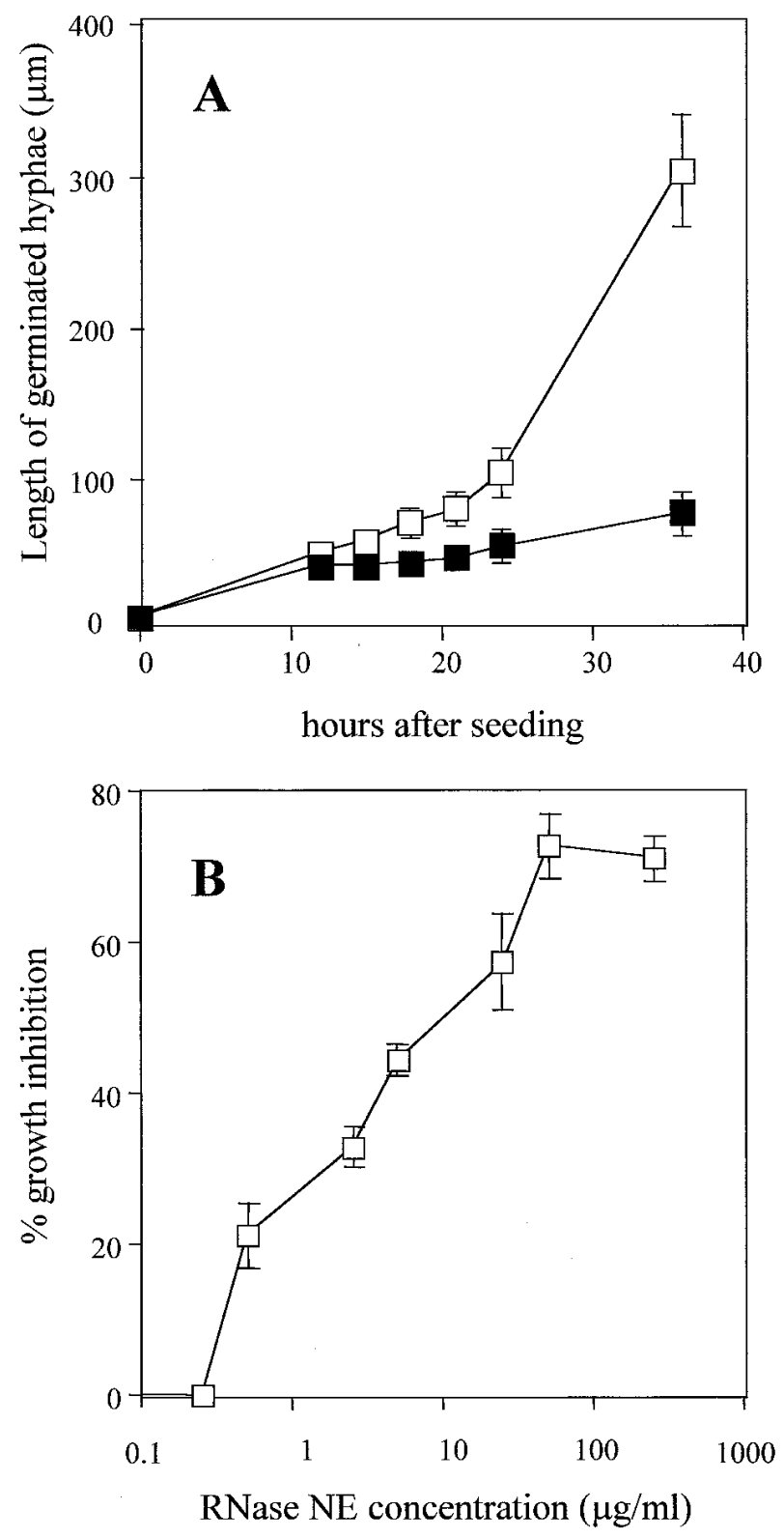

Fig. 4. Antimicrobial activity of purified RNase NE. A, Kinetics of Phytophthora parasitica primary hyphal elongation. Length of hyphae \pm standard error of the mean was measured at the indicated time points in MES buffer (white square) and in the presence of $50 \mu \mathrm{g}$ of RNase NE per $\mathrm{ml}$ (black square). B, Dose-effect curve determined after $24 \mathrm{~h}$ of incubation of Phytophthora parasitica zoospores. The percentages of growth inhibition were defined by the ratio of the average length of hyphae in the presence of RNase NE at the tested concentrations to the length of hyphae in the control without RNase NE. Results were analyzed statistically by means of a Student's $t$ test. Differences between RNase NEtreated and untreated conditions were statistically significant $(P<0.001$, $n=3$ ) when the concentrations of RNase NE reached $1 \mu \mathrm{g}$ per ml. nizes leaf tissues than it is in vitro. One interpretation of this result is that, in susceptible plants, RNase NE is enzymatically active but is not capable, by itself, of fully restricting hyphal elongation when $P$. parasitica grows in host tissues with all the nutrients required for its complete development. Thus, RNase $\mathrm{NE}$ might act in concert with other defense molecules to participate in the inhibition of pathogen growth in resistant plants. A second, related interpretation is that its ribonuclease activity is inhibited in planta and a reversion of this inhibition requires the activation of defense responses. The fact that early up-regulation of RNase activity is an event that occurs during the expression of the SAR phenotype after challenge inoculation (Lusso and Kuc 1995; Galiana et al. 1997) corroborates this hypothesis. The local accumulation in response to inoculation, taken together with the extracellular localization, the demonstration of a direct antimicrobial activity, and the active doses allows us to propose that RNase NE is involved as an early barrier of plant defense in the apoplastic compartment.

Until now, the only biological function demonstrated for extracellular plant RNases was the inhibition of pollen tube elongation in gametophytic self-incompatibility. S-RNases are secreted into style mucilage, where they abort the growth of pollen bearing the same S-allele (Clarke and Newbigin 1993). We provide experimental support that this type of enzyme has a second biological activity, which is also a cytotoxic activity. The S-like RNase NE and the S-RNases inhibit the elongation of fungal and pollen germ tubes, respectively. Using site-directed mutagenesis, we have shown a correlation between the antimicrobial activity and the enzymatic activity. His 97 and His39 residues are highly conserved in the RNase T2 family and have been shown to be necessary for enzymatic activity in the case of RNase Rh and S-RNases (Oghi et al. 1992; Parry et al. 1997). Based on these results, we chose to mutate His97 to Phe. The mutated protein lost its enzymatic activity as well as its cytotoxic activity, demonstrating that the ribonucleasic activity of RNase NE is required for the inhibition of germ tube elongation. In the case of S-RNases, a correlation between cytotoxic activity and enzymatic activity has also been demonstrated using a transgenesis strategy. Transgenic plants expressing an exogenous S-RNase do not inhibit tube elongation of pollen with the same allele when the S-RNase is mutated for one of the two histidine residues necessary for the catalytic activity (Huang et al. 1994). The possibility that gametophytic self-incompatibility may have evolved through the recruitment of an ancient ribonuclease involved in defense mechanisms against pathogens for use in defense against "invasion" by self pollen tubes has already been postulated (Lee et al. 1992). Demonstration of the ribonuclease-dependent antimicrobial activity of an S-like RNase, together with the similarity of effects, supports this hypothesis. The comparison of the action of $\mathrm{S}$-RNase in pollen-pistil interactions with that of RNase NE in plant-microbe interactions may allow a better understanding of their respective roles in each of these interactions.

Although we have not yet established the mechanism of the cytotoxic action of RNase NE, our results suggest that NE protein stops hyphal growth by degrading RNAs. Such a degradation of RNAs would lead to the arrest of protein synthesis, which would, in turn, explain an arrest of hyphal elongation. This model implies a translocation system of the protein from the extracellular space to the fungal cytosol where it would cleave RNAs. Such a model has already been proposed for the allele-specific inhibition of pollen by S-RNase in the Solanaceae family (Dodds et al. 1996a; Kao et al. 1996). Luu and associates (2000) have shown the accumulation of an S-RNase from Solanum chacoense in the cytoplasm of all pollen tube haplotypes growing in vivo. This result supports a model for self-incompatibility in which S-RNases are taken up by pollen 
tubes without specificity and an RNase inhibitor must be present inside the pollen tubes. Some bacterial toxins are also internalized into host cells before killing them. For example, a Shiga toxin produced by Shigella dysenteriae is endocytosed and transported to the trans-Golgi network (Sandvig et al. 1992). The toxin is further transported to the endoplasmic reticulum, where translocation of the A-chain to the cytosol may take place. The A-chain is an $\mathrm{N}$-glycosidase that cleaves off a single adenine residue from the $28 \mathrm{~S}$ rRNA of the $60 \mathrm{~S}$ ribosomal subunit, resulting in the inhibition of protein synthesis (Garred et al. 1997). The RNase NE could follow the same intracellular trafficking, considering that brefeldin A, which disrupts Golgi structures, also affects the antimicrobial activity of RNase NE and that growth of hyphae is accompanied by an accumulation of Golgi vesicles in the expanding tip for regulated exocytosis and probably endocytosis (Hoffmann and Mendgen 1998; Wedlich-Soldner et al. 2000). Another hypothesis is that the cytotoxic activity of RNase NE could involve a modification of the fungal membrane. Indeed, it has recently been proposed that the yeast RNase T2, RNy1, may act through its ribonuclease activity as a regulator of membrane permeability (MacIntosh et al. 2001).

Different cytotoxic activities have been observed for bacterial and animal RNases. Thus, an antitumoral activity has been demonstrated for different RNases (Youle and D'Alessio 1997). The bovine seminal RNase BS also has an immunosuppressive and aspermatogenic action (D'Alessio et al. 1997). Moreover, antiviral and antibacterial activities have been observed for different RNases. Based on these biological activities, investigations were undertaken to evaluate these RNases as tools for anticancer therapy (Piccoli et al. 1999) and also for crop protection against viral diseases (Mitra et al. 1996; Watanabe et al. 1995). Screening for peptides exhibiting an antifungal effect has led to the discovery of a protein from ginseng roots that has RNase activity (Wang and $\mathrm{Ng}$ 2000). These results, taken together with the properties of the tobacco RNase NE described here, indicate a new biological effect for these enzymes. Therefore, plant RNases could also be used to develop new strategies against pathogenic diseases.

\section{MATERIALS AND METHODS}

Plant material and fungi cultures.

Tobacco plant (Nicotiana tabacum L. cv Xanthi nc.) growth, $P$. parasitica growth, zoospore release, and inoculation procedures were performed as previously described by Hugot et al. (1999). F. oxysporum f. sp. radicis lycopersici was generously provided by C. Alabouvette (INRA, Dijon, France). For the production of conidia, mycelium was cultivated at $24^{\circ} \mathrm{C}$ under continuous light conditions for 1 week on malt medium containing 2\% agar. The conidia were released after addition of water and vigorous mixing for $30 \mathrm{~s}$.

\section{Inoculation procedures.}

Experiments were performed on 7- to 8-week-old tobacco plants. $P$. parasitica was inoculated by infiltrating a $50 \mu \mathrm{l}$ suspension containing 100 zoospores into the parenchymatic tissue. In each experiment, two or three infiltrations of zoospore suspension per leaf were performed on at least five consecutive leaves. The zoospore suspension was infiltrated into leaves in the presence of $50 \mu \mathrm{g}$ RNase NE, RNase NE-H97F, or bovine serum albumin proteins per $\mathrm{ml}$. The areas of disease symptoms in each leaf were measured 2 days after inoculation.

\section{Plasmid construction.}

The pPIC9 vector (Invitrogen, Groningen, The Netherlands) allows the methanol-inducible expression of the recombinant protein in Pichia pastoris and its secretion using the Saccharomyces cerevisiae $\alpha$-factor secretion signal. In order to clone the NE gene in frame with the initiation codon of the signal sequence, the DNA fragment containing the Nicotiana alata RNase NE encoding sequence (nucleotides 107 to 721 ) was synthesized by polymerase chain reaction (PCR), using purified pNE1 plasmid (Dodds et al. 1996b) as a template with the sense and antisense primers corresponding to oligonucleotides 5'-TACCGCTCGAGAAAAGAGAGGCTGAAGCTGCTCAAGA-TTTCGACTT-3' and 5'-TTGCGCTCGAGAGCTTAGAATGTTGGGAA-3', respectively. The pPIC9-NE plasmid used for expressing the RNase NE was constructed by ligation of the pPIC9 vector with amplified RNase NE sequences and by using XhoI restriction sites before the NE coding sequence in the sense and antisense primers (nucleotides in bold type). Transformed Escherichia coli were selected on ampicillin-containing media $(50 \mu \mathrm{g} / \mathrm{ml})$. Clones were confirmed by DNA sequence determination (Genome Express S.A., Grenoble, France).

\section{Site-Directed Mutagenesis.}

The pPIC9-NE-H97F plasmid used for expressing the mutated RNase NE in Pichia pastoris was obtained by PCR sitedirected mutagenesis using a QuickChange site-directed mutagenesis kit purchased from Stratagene (La Jolla, California, U.S.A.). PCR was done with the pPIC9-NE plasmid as a template and the sense and antisense primers corresponding to oligonucleotides 5'-CATGAATGGGAAAAATTTGGCACTTGTTCTG-3' and 5'-CAGAACAAGTGCCAAATTTTTCCCA-

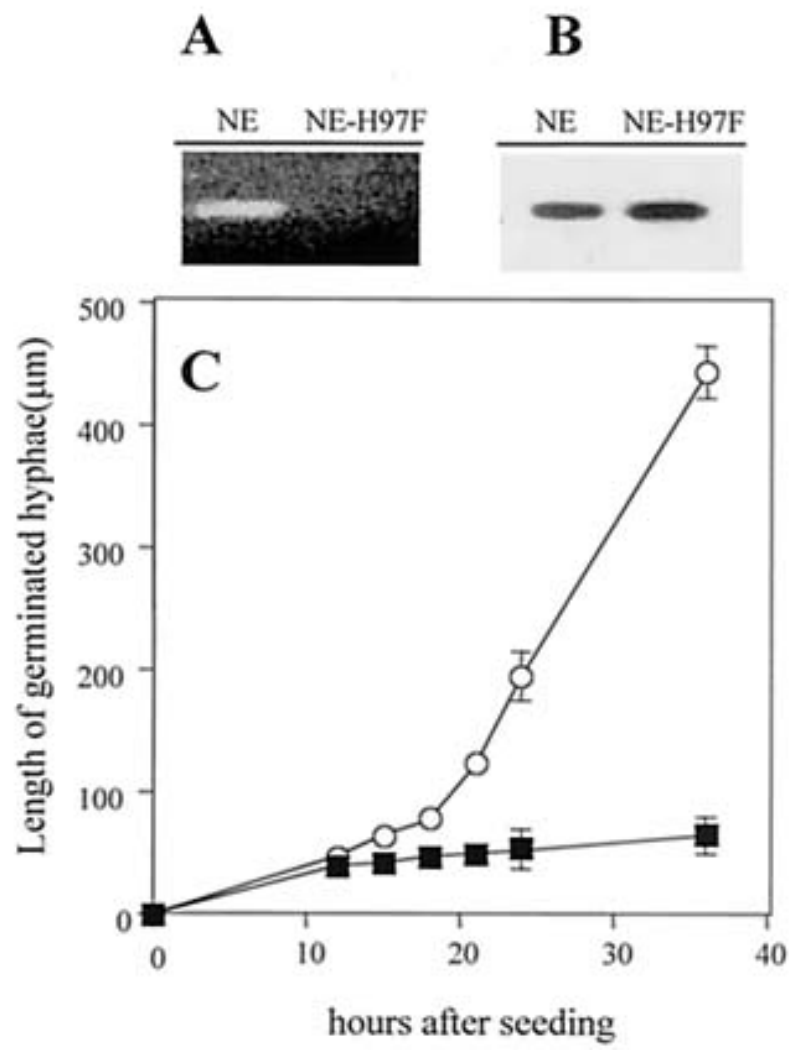

Fig. 5. Influence of enzymatic activity on the antimicrobial activity of RNase NE. A, RNase activity gel assay and $\mathbf{B}$, Western blot analysis for purified NE and NE-H97F proteins (50 ng/lane). C, Kinetics of Phytophthora parasitica hyphal elongation. Length of hyphae \pm the standard error of the mean was measured at the indicated time points in the presence of $50 \mu \mathrm{g}$ of RNase NE per ml (black square) or of $50 \mu \mathrm{g}$ of RNase NE-H97F per ml (white circle). Differences between RNase NE-treated and RNase NE-H97F-treated conditions were statistically significant ( $\mathrm{P}$ $<0.001, \mathrm{n}=3$ ) when the incubation time reached $18 \mathrm{~h}$. 
TTCATG-3', respectively, which include the codon corresponding to the His-97 residue mutated for a Phe (codon in bold type). After transformation with the PCR products, E. coli clones were selected on ampicillin-containing media (50 $\mu \mathrm{g} / \mathrm{ml})$. The point mutation $\mathrm{H} 97 \mathrm{~F}$ and the NE coding region were confirmed by DNA sequence determination (Genome Express S.A).

\section{Expression and purification of NE recombinant proteins.}

The yeast Pichia pastoris strain GS115 (Invitrogen) was transformed with linearised pPIC9-NE or pPIC9-NE-H97F plasmids at the SacI site according to the manufacturer's instructions. After yeast clone selection, efficiency of RNase NE or mutated RNase NE secretion was analyzed by RNase activity staining gel assays or SDS/PAGE, or both. NE proteins were purified from the culture filtrate by column chromatography. After concentration by tangential-flow ultrafiltration using an Amicon miniplate bioconcentrator (Millipore, St. Quentin Yvelines, France) and dialysis against water, the supernatant was loaded onto a Macro-Prep HQ anion-exchange support (Bio-Rad, Hercules, CA, U.S.A.) equilibrated with $20 \mathrm{mM}$ $\mathrm{KH}_{2} \mathrm{PO}_{4} / \mathrm{K}_{2} \mathrm{HPO}_{4}$, $\mathrm{pH}$ 7. Elution was performed with three increasing concentrations of $\mathrm{NaCl}(0.25,0.5$, and $1 \mathrm{M})$ in the same buffer. The NE protein-containing fraction $(0.25 \mathrm{M}$ $\mathrm{NaCl}$ ) was applied to a reversed phase column (Synchroprep C18, $30 \mu \mathrm{m}, 300 \AA$ A; Synchrom Inc., Ste Foy la Grande, France) equilibrated with $0.25 \mathrm{M} \mathrm{NaCl}, 20 \mathrm{mM} \mathrm{KH}_{2} \mathrm{PO}_{4} / \mathrm{K}_{2} \mathrm{HPO}_{4}, \mathrm{pH}$ 6. The column was washed with $20 \%$ (vol/vol) $\mathrm{CH}_{3} \mathrm{CN}, 0.1 \%$ (vol/vol) triflouroacetic acid (TFA), and elution was performed by application of three increasing concentrations of aqueous $\mathrm{CH}_{3} \mathrm{CN}(30,40$, and $60 \%)$ in the presence of $0.1 \%$ ( $\left.\mathrm{vol} / \mathrm{vol}\right)$ TFA. After evaporation of $\mathrm{CH}_{3} \mathrm{CN}$ and dialysis against water, the purified RNase NE was lyophilized. During the purification procedure, all fractions were analyzed by HPLC to identify RNase NE-containing fractions.

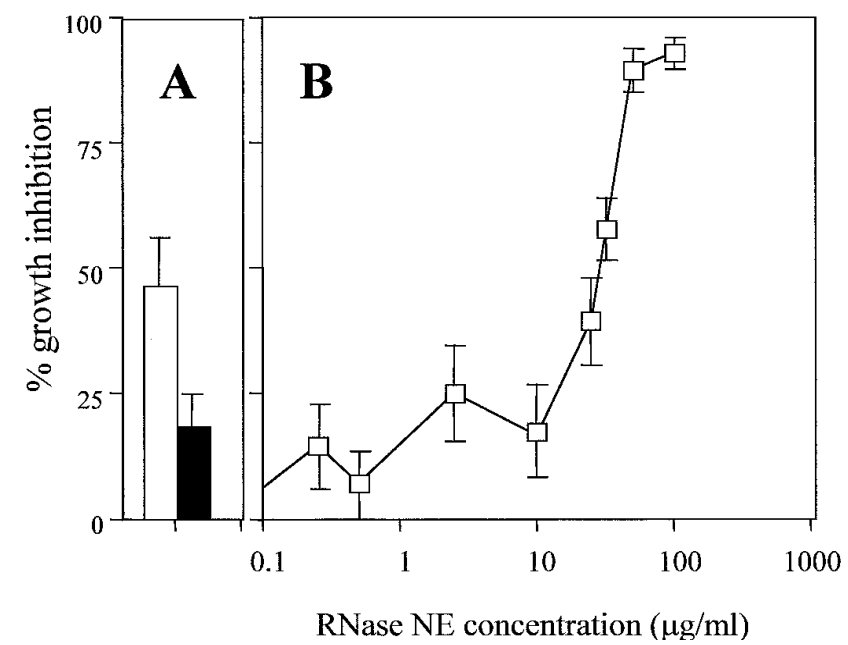

Fig. 6. Influence of Brefeldin A on the antimicrobial activity of RNase NE. A, Phytophthora parasitica zoospores were incubated for $24 \mathrm{~h}$ with (black bar) or without (white bar) Brefeldin A $(5 \mu \mathrm{g} / \mathrm{ml})$ and in the presence of RNase NE $(50 \mu \mathrm{g} / \mathrm{ml})$. The percentages of growth inhibition were defined by the ratio of the average length of hyphae in the presence of RNase NE at the tested concentrations to the length of hyphae in the control without RNase NE. Differences for RNase NE effect between triflouroacetic acid brefeldin A-treated and untreated conditions were statistically significant $(\mathrm{P}=0.0002, \mathrm{n}=3)$. B, Dose-effect curve determined after $24 \mathrm{~h}$ of incubation of zoospores in the presence of $5 \mu \mathrm{g}$ of Brefeldin A per $\mathrm{ml}$. Differences between RNase NE-treated and untreated conditions were statistically significant $(\mathrm{P}<0.001, \mathrm{n}=3)$ when the concentrations reached 25 to $50 \mu \mathrm{g}$ of RNase NE per ml.

\section{HPLC analysis.}

During the purification procedure, a HPLC system (Waters, Milford, MA, U.S.A.) was used for fraction analysis. Solvent A contained $20 \%$ (vol/vol) $\mathrm{CH}_{3} \mathrm{CN}$ and $0.1 \%$ (vol/vol) TFA, and solvent $\mathrm{B}$ contained $70 \%$ (vol/vol) $\mathrm{CH}_{3} \mathrm{CN}$ and $0.1 \%$ (vol/vol) TFA. The column was equilibrated in solvent A before injection. An elution gradient ranging from 0 to $100 \%$ of solvent B in solvent A was applied to the samples for 0 to $25 \mathrm{~min}$. Elution was monitored at $280 \mathrm{~nm}$ with a Waters 996 diode array detector (200 to $400 \mathrm{~nm}$; resolution, $1.2 \mathrm{~nm}$ ) (Waters).

\section{RNase activity assays.}

RNase activity staining gel assays were performed as previously described by Yen and Green (1991). RNase activity was estimated by measuring the hyperchromicity upon cleavage of polynucleotides in $50 \mathrm{mM}$ acetate or phosphate buffer ( $\mathrm{pH} 4.5$ to 8). The yeast RNAs Torulopsis utilis-Sigma (concentration ranging from 0 to $40 \mu \mathrm{g} / \mathrm{ml}$ ) used as substrate were mixed with the enzyme $(0.02 \mu \mathrm{g} / \mathrm{ml})$ at $t=0$ in a spectrophotometer tube. Increase in optical density (OD) at $260 \mathrm{~nm}$ was monitored for $10 \mathrm{~min}$, and initial velocity (Vo) was calculated from the curve OD-time curve. The specific activity was expressed as the A260 units of Torulopsis utilis RNA released into acid-soluble form by $1 \mathrm{mg}$ of the protein in $1 \mathrm{~min}$ at $24^{\circ} \mathrm{C}$ at $\mathrm{pH} 5.5$.

\section{Immunoblotting procedure.}

Rabbit polyclonal antibodies were raised against RNase NE by using as immunogen the purified recombinant protein produced in Pichia pastoris. Analysis by Western blotting was done for either NE and NE-H97F purified protein from Pichia

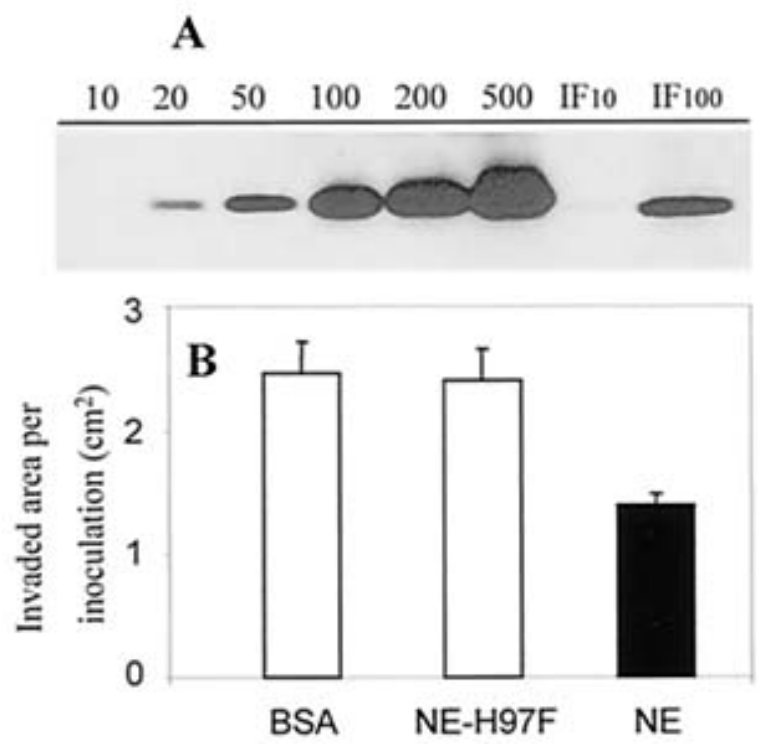

Fig. 7. A, Detection of RNase NE after Phytophthora parasitica inoculation. Amounts of 10, 20, 50, 100, 200, and $500 \mathrm{ng}$ of purified RNase NE were used as controls. Intercellular fluid was prepared from leaves $24 \mathrm{~h}$ after inoculation with the oomycete. Controls and intercellular fluids (IF10 for $10 \mu \mathrm{l}$ and IF100 for $100 \mu \mathrm{l}$ reduced to $10 \mu \mathrm{l}$ after evaporation under vacuum) were subjected to sodium dodecyl sulfate-polyacrylamide gel electrophoresis and gel blotting. Proteins were then incubated with rabbit antibodies against RNase NE. B, Exogenous application of RNase $\mathrm{NE}$ and $P$. parasitica in planta growth. Leaves were inoculated with $P$. parasitica zoospores in the presence of RNase NE, protein NE-H97F, or bovine serum albumin $(50 \mu \mathrm{g} / \mathrm{ml})$. The areas of disease symptoms were measured 2 days after inoculation. Each bar represents the mean \pm standard deviation of three replicates from three different experiments. A replicate corresponds to 10 inoculated areas on five leaves of one plant. Significant differences were noted between the NE treatment and the bovine serum albumin or protein NE-H97F treatments $(\mathrm{P}<0.001, \mathrm{n}=3)$. 
pastoris or leaf extract from inoculated areas. Intercellular fluids were prepared in $50 \mathrm{mM}$ Tris- $\mathrm{HCl}, \mathrm{pH} 7$, buffer as described by Hammond-Kosak (1992). After recovery of intercellular fluids, leaf tissues were ground under liquid nitrogen and resuspended in $50 \mathrm{mM}$ Tris- $\mathrm{HCl}, \mathrm{pH}$ 7, buffer. Intracellular fractions were obtained after centrifugation at $15,000 \times g$ for $10 \mathrm{~min}$ at $4^{\circ} \mathrm{C}$ and recovery of the supernatant. After SDS/PAGE on $15 \%$ gel, the proteins were transferred electrophoretically onto nitrocellulose membranes and incubated with rabbit antibodies against RNase NE or against malate dehydrogenase (Miller et al. 1998). Detection of the antigen-antibody complexes was carried out with the ECL immunoblot assay kit (Amersham Pharmacia Biotech, Orsay, France) using goat peroxydase-conjugated IgG against rabbit immunoglobulins (Sigma, L'Isle d'Abeau Chesnes, France).

\section{In vitro antimicrobial assays.}

In vitro antimicrobial assays were performed on 12-well slides. In each well, a $20 \mu \mathrm{l}$ suspension containing 250 P. parasitica zoospores or $250 \mathrm{~F}$. oxysporum conidia in $10 \mathrm{mM}$ MES, $\mathrm{pH} 5.6$, was incubated for 1 to $24 \mathrm{~h}$ at $25^{\circ} \mathrm{C}$ and $100 \%$ humidity in the presence of various concentrations $(0$ to $100 \mu \mathrm{g} / \mathrm{ml})$ of NE or NE-H97F proteins. For brefeldin A treatment, the suspensions were adjusted to $4 \mu \mathrm{g}$ of brefeldin A (Sigma) per ml from a $1000 \mu \mathrm{g} / \mathrm{ml}$ stock solution in methanol. In these experiments controls were treated with $0.5 \%$ methanol. Two hours after the start of incubation, the cells were observed by microscopy to monitor the mobility and hyphal development. After the beginning of incubation ( $24 \mathrm{~h}$ ), the length of growing hyphae was measured on a television screen connected to the microscope. Inhibitory activities of NE proteins on primary hyphae growth were determined by comparison to control samples. For all data presented, values are the mean of two replicates from one representative of three experiments. A replicate corresponds to at least twenty fungal hyphae.

\section{ACKNOWLEDGMENTS}

We thank E. Newbigin (University of Melbourne) for his generous gift of NE cDNA, S. Miller (University of Minnesota) for her generous gift of antibodies against alfalfa malate dehydrogenase, and R. Delbos (INRA Bordeaux) for the production of antibodies directed against NE. We are also grateful to C. Weiss (American Cyanamid-BASF) and J. Feyereisen for editing the manuscript. This work was supported by a fellowship of the Ministère de la Recherche et de l'Education Nationale to K. Hugot.

\section{LITERATURE CITED}

Bariola, P. A., Howard, C. J., Taylor, C. B., Verburg, M. T., Jaglan, V. D., and Green, P. J. 1994. The Arabidopsis ribonuclease gene RNS1 is tightly controlled in response to phosphate limitation. Plant J. 6:673685 .

Chardin, P., and McCormick, F. 1999. Brefeldin A: The advantage of being uncompetitive. Cell 97:153-155.

Clarke, A. E., and Newbigin, E. 1993. Molecular aspects of self-incompatibility in flowering plants. Annu. Rev. Genet. 27:257-279.

D’Alessio, G., Di Donato, A., Mazzarella, L., and Piccoli, R. 1997. Seminal Ribonuclease: The Importance of Diversity. Pages 383-423 in: Ribonucleases. Structures and Functions. G. D'Alessio and J. Riordan, eds. Academic Press, New York.

Dodds, P. N., Clarke, A. E., and Newbigin, E. 1996a. A molecular perspective on pollination in flowering plants. Cell 85:141-144.

Dodds, P. N., Clarke, A. E., and Newbigin, E. 1996b. Molecular characterization of an S-like RNase of Nicotiana alata that is induced by phosphate starvation. Plant Mol. Biol. 31:227-238.

Farkas, G. L. 1982. Ribonucleases and ribonucleic acid breakdown. Pages 224-262 in: Encyclopedia of Plant Physiology. New Series. Volume 14B. Nucleic Acids and Proteins in Plants II. Structure, Biochemistry and Physiology of Nucleic Acids. Springer-Verlag, Berlin.

Galiana, E., Bonnet, P., Conrod, S., Keller, H., Panabieres, F., Ponchet, M., Poupet, A., and Ricci, P. 1997. RNase activity prevents the growth of a fungal pathogen in tobacco leaves and increases upon induction of systemic acquired resistance with elicitin. Plant Physiol. 115:15571567.

Garred, O., Dubinina, E., Polesskaya, A., Olsnes, S., Kozlov, J., and Sandvig, K. 1997. Role of the disulfide bond in Shiga toxin A-chain for toxin entry into cells, J. Biol. Chem. 272:11414-11419.

Green, P. J. 1994. The ribonucleases of higher plants. Annu. Rev. Plant Mol. Biol. 45:421-445.

Hammond-Kosak, K. E. 1992. Preparation and analysis of intercellular fluid. Pages 15-22 in: Molecular Plant Pathology: A Practical Approach, Vol II. S. J. Gurr, M. J. McPherson, and D. J. Bowles, eds. IRL Press at Oxford University Press, Oxford.

Hoffmann, J., and Mendgen, K. 1998. Endocytosis and membrane turnover in the germ tube of Uromyces fabae. Fungal Genet. Biol. 24:7785.

Huang, S., Lee, H. S., Karunanandaa, B., and Kao, T. H. 1994. Ribonuclease activity of Petunia inflata $\mathrm{S}$ proteins is essential for rejection of self-pollen. Plant Cell 6:1021-1028.

Hugot, K., Aime, S., Conrod, S., Poupet, A., and Galiana, E. 1999. Developmental regulated mechanisms affect the ability of a fungal pathogen to infect and colonize tobacco leaves. Plant J. 20:163-170.

Irie, M. 1997. RNase T1/RNase T2 Family RNases. Pages 101-130 in: Ribonucleases: Structures and Functions. G. D'Alessio and J. Riordan, eds. Academic Press, New York.

Kao, T. H., and McCubbin, A. G. 1996. How flowering plants discriminate between self and non-self pollen to prevent inbreeding, Proc. Natl. Acad. Sci. U.S.A. 93:12059-12065.

Kock, M., Loffler, A., Abel, S., and Glund, K. 1995. cDNA structure and regulatory properties of a family of starvation-induced ribonucleases from tomato. Plant Mol. Biol. 27:477-485.

Lee, H. S., Singh, A., and Kao, T. 1992. RNase X2, a pistil-specific ribonuclease from Petunia inflata, shares sequence similarity with solanaceous S proteins. Plant Mol. Biol. 20:1131-1141.

Lee, H. S., Huang, S., and Kao, T. 1994. S proteins control rejection of incompatible pollen in Petunia inflata, Nature 367:560-563.

Lers, A., Khalchitski, A., Lomaniec, E., Burd, S., and Green, P. J. 1998. Senescence-induced RNases in tomato. Plant Mol. Biol. 36:439-449.

Lusso, M., and Kuc, J. 1995. Increased activities of ribonuclease and protease after challenge in tobacco plants with induced systemic resistance. Physiol. Mol. Plant Pathol. 47:419-428.

Luu, D. T., Qln, X., Morse, D., and Cappadocia, M. 2000. S-RNase uptake by compatible pollen tubes in gametophytic self-incompatibility. Nature 407:649-651.

McClure, B. A., Haring, V., Ebert, P. R., Anderson, M. A., Simpson, R. J., Sakiyama, F., and Clarke, A. E. 1989. Style self-incompatibility gene products of Nicotiana alata are ribonucleases. Nature 342:955-957.

MacIntosh, G. C., Bariola, P. A., Newbigin, E., and Green P. 2001. Characterization of Rny1, the Saccharomyces cerevisiae member of the T2 RNase family of RNases: Unexpected functions for ancient enzymes? Proc. Natl. Acad. Sci. U.S.A. 98:1018-1023.

Miller, S. S., Driscoll, B. T., Gregerson, R. G., Gantt, J. S., and Vance, C. P. 1998. Alfalfa malate dehydrogenase (MDH): Molecular cloning and characterization of five different forms reveals a unique nodule- enhanced MDH. Plant J. 15:173-184.

Mitra, A., Higgins, D. W., Langenberg, W. G., Nie, H., Sengupta, D. N., and Silverman, R. H. 1996. A mammalian 2-5A system functions as an antiviral pathway in transgenic plants. Proc. Natl. Acad. Sci. U.S.A. 93:6780-6785.

Murfett, J., Atherton, T. L., Mou, B., Gasser, C. S., and McClure, B. A. 1994. S-RNase expressed in transgenic Nicotiana causes S-allelespecific pollen rejection. Nature 367:563-566.

Niderman, T., Genetet, I., Bruyere, T., Gees, R., Stintzi, A., Legrand, M., Fritig, B., and Mosinger, E. 1995. Pathogenesis-related PR-1 proteins are antifungal. Isolation and characterization of three 14-kilodalton proteins of tomato and of a basic PR-1 of tobacco with inhibitory activity against Phytophthora infestans. Plant Physiol. 108:17-27.

Ohgi, K., Horiuchi, H., Watanabe, H., Iwama, M., Takagi, M., and Irie, M. 1992. Evidence that three histidine residues of a base non-specific and adenylic acid preferential ribonuclease from Rhizopus niveus are involved in the catalytic function. J. Biochem. 112:132-138.

Parry, S., Newbigin, E., Currie, G., Bacic, A., and Oxley, D. 1997. Identification of active-site histidine residues of a self-incompatibility ribonuclease from a wild tomato. Plant Physiol. 115:1421-1429.

Piccoli, R., Di Gaetano, S., De Lorenzo, C., Grauso, M., Monaco, C., Spalletti-Cernia, D., Laccetti, P., Cinatl, J., Matousek, J., and D'Alessio, G. 1999. A dimeric mutant of human pancreatic ribonuclease with selective cytotoxicity toward malignant cells Proc. Natl. Acad. Sci. U.S.A. 96:7768-7773.

Sandvig, K., Garred, O., Prydz, K., Kozlov, J. V., Hansen, S. H., and van Deurs, B. 1992. Retrograde transport of endocytosed Shiga toxin to 
the endoplasmic reticulum. Nature 358:510-512.

Schrauwen, J., and Linskens, H. F. 1972. Ribonucleases in styles. Planta 102:277-285.

Sela-Buurlage, M. B., Ponstein, A. S., Bres-Vloemans, S. A., Melchers, L. S., Elzen, P. J. M. v. d., and Cornelissen, B. J. C. 1993. Only specific tobacco (Nicotiana tabacum) chitinases and beta -1,3glucanases exhibit antifungal activity. Plant Physiol. 101:857-863.

Taylor, C. B., Bariola, P. A., delCardayre, S. B., Raines, R. T., and Green, P. J. 1993. RNS2: A senescence-associated RNase of Arabidopsis that diverged from the S-RNases before speciation. Proc. Natl. Acad. Sci. U.S.A. 90:5118-5122.

Terras, F. R. G., Goderis, I. J., Van Leuven, F., Vanderleyden, J., Cammue, B. P. A., and Broekaert, W. F. 1992. In vitro antifungal activity of a radish (Raphanus sativus L.) seed protein homologous to nonspecific lipid transfer proteins. Plant Physiol. 100:1055-1058

Wang, H. X., and Ng, T. B. 2000. Quinqueginsin, a novel protein with anti-human immunodeficiency virus, antifungal, ribonuclease and cell- free translation-inhibitory activities from American ginseng roots. Biochem. Biophys. Res. Commun. 269:203-208.

Watanabe, Y., Ogawa, T., Takahashi, H., Ishida, I., Takeuchi, Y., Yamamoto, M., and Okada, Y. 1995. Resistance against multiple plant viruses in plants mediated by a double stranded-RNA specific ribonuclease. FEBS (Fed. Eur. Biochem. Soc.) Lett. 372:165-168.

Wedlich-Soldner, R., Bolker, M., Kahmann, R., and Steinberg, G. 2000. A putative endosomal t-SNARE links exo- and endocytosis in the phytopathogenic fungus Ustilago maydis. Embo J. 19:1974-1986.

Ye, Z. H., and Droste, D. L. 1996. Isolation and characterization of cDNAs encoding xylogenesis-associated and wounding-induced ribonucleases in Zinnia elegans. Plant Mol. Biol. 30:697-709.

Yen, Y., and Green, P. J. 1991. Identification of the major ribonucleases of Arabidopsis thaliana. Plant Physiol. 97:1487-1493.

Youle, R. J., D’Alessio, G. 1997. Antitumor RNases. Pages 491-514 in: Ribonucleases: Structures and Functions. G. D'Alessio and J. Riordan, eds. Academic Press, New York. 